\title{
PROPUESTA DE HISTORIA ESPECTACULAR DE LA PARODIA DEL ROMANTICISMO ${ }^{1}$
}

\author{
Víctor Manuel PELÁEz PÉRez \\ Universidad de Alicante
}

\section{El Romanticismo y la parodia teatral}

La historia de las parodias de los dramas románticos, a pesar de carecer de un estudio monográfico sistemático y global, ha sido reconstruida gracias a una dilatada serie de investigaciones parciales que, además de aumentar la nómina de textos paródicos, han descrito los recursos textuales más recurrentes que los autores emplean en el proceso de cambio de código del discurso original remedado al paródico. De esos estudios destaca el volumen Romanticismo 5 (La sonrisa romántica), que supone la aproximación más completa realizada hasta el momento acerca de parodia romántica. No obstante, dichos trabajos centran su interés en el texto dramático, como lógica consecuencia del carácter de introducción que los presidía. En consecuencia, nuestro objetivo es doble: sistematizar el conjunto de parodias del Romanticismo, aportando un criterio unificador que reúna la heterogeneidad de investigaciones al respecto, y elaborar una propuesta de historia de los espectáculos románticos, que trascienda los límites del texto dramático (Bobes 1997). Evidentemente, el presente trabajo se caracterizará por un enfoque de aproximación inicial, que, antes que resolver la problemática de la historia de la parodia del Romanticismo escénico, desarrolle las bases de una futura historia

'Este trabajo se enmarca en el proyecto de investigación La parodia teatral en España, becado por la Generalitat Valenciana. 
de los espectáculos paródicos románticos, integrada en el marco de una historia más general del período áureo de los espectáculos paródicos.

Previamente a la sistematización de la realidad espectacular paródica que desarrollaremos en este trabajo, son necesarias las siguientes consideraciones: en primer lugar, manejamos una concepción lúdica del género paródico, según la cual éste ha de entenderse como juego literario con la competencia teatral del público; en segundo lugar, dicha actividad lúdica toma como subtexto un espectáculo dramático, no un texto, porque el receptor decimonónico era, más que lector, fundamentalmente espectador; como consecuencia, en tercer lugar, prestaremos mayor atención a los elementos sígnicos del nivel espectacular que contribuyan a parodiar las puestas en escena románticas, dejando a un lado el nivel textual, ya suficientemente estudiado; y en cuarto y último lugar, prescindiremos del estudio de la saga paródica del drama romántico Don Juan Tenorio, de José Zorrilla, debido al prolijo número de remedos que suscitó (Serrano 1996), imposibles de abarcar en una investigación de las características de la presente.

Desde el punto de vista de la relevancia histórica, las parodias del Romanticismo, junto con las del discurso operístico, constituyen el conjunto más significativo de la producción paródica del período dorado ${ }^{2}$. Cronológicamente, los remedos se extienden desde 1837, fecha del estreno de Muérete... iy verás!, de Bretón de los Herreros, hasta 1918, año de La venganza de don Mendo, de Pedro Muñoz Seca. Ambos son, por otra parte, los espectáculos más emblemáticos de este bloque. En el intervalo temporal que los separa los escenarios españoles conocen el estreno de un elevado número de parodias románticas, adscritas a categorías varias, pero nunca conocerán el éxito que obtuvieron los dos hitos señalados ${ }^{3}$. Sí son, no obstante, ejemplificativas de la saga paródica que la retórica romántica generó en los teatros nacionales durante los dos segundos tercios del siglo XIX y primeros años del XX.

Esta dilatada cronología de los estrenos corrobora la naturaleza no circunstancial de los remedos paródicos que constituyen el corpus acotado. Es frecuente en el ámbito de la parodia teatral el aprovechamiento del éxito circunstancial,

2 Puede consultarse una clasificación del período áureo de las parodias en el portal temático La parodia teatral en España, dirigido por Juan A. Ríos y publicado en la página electrónica de la Biblioteca Virtual Miguel de Cervantes (www.cervantesvirtual.com).

A título orientativo, indicamos que el espectáculo de Bretón de los Herreros mantuvo una notable vigencia escénica durante toda la segunda mitad del siglo XIX, llegando a ser incluso la pieza predilecta de la actriz María Guerrero, que lo representó en varias ocasiones (Sánchez Salas 1998). El número de ediciones impresas de este texto también es significativo de la difusión que alcanzó. Por otro lado, el astracán de Pedro Muñoz Seca mantiene incluso en la actualidad una constante presencia escénica, siendo uno de los espectáculos más relevantes en la historia teatral del siglo XX, a pesar de que hoy ya no se reconozca la faceta paródica de esta caricatura y sólo mantenga intacta su fuerza cómica. 
inmediato, de un espectáculo dramático, con el objetivo de que el público mantenga reciente la referencia metateatral al discurso remedado. Son muchos los espectáculos que experimentaron éxitos atronadores y que relativamente poco después dejaron de tener vigencia escénica y, en consecuencia, de formar parte de la competencia de los espectadores. Así cabe entender, por ejemplo, los dramas de José Echegaray, que constituyen la base esencial de uno de los bloques más productivos de parodia teatral. No ocurrió igual con los dramas románticos, porque, tras el período de eclosión escénica de la ideología romántica, no decayó su vigencia escénica. Los títulos más representativos del Romanticismo teatral conocieron reposiciones en cada temporada y, gracias a ello, pasaron a formar parte de la competencia teatral permanente de los espectadores. A partir de esta circunstancia es, por tanto, plenamente inteligible la creación de parodias no sujetas a unas determinadas fechas próximas al estreno del espectáculo remedado.

No obstante lo apuntado, no tardaron en aparecer los primeros remedos del teatro romántico, que dieron respuesta a peticiones como la formulada ya en 1832 por El Literato Rancio: «Si Cervantes acabó con los libros de caballerías, ahora haría falta otro Cervantes para acabar con la literatura romántica» (Llorens 1979, págs. 225); y nosotros añadiríamos, con la mala literatura romántica, aquélla de la que se burlan Mariano José de Larra y Mesonero Romanos, entre otros, aquélla que hace uso de los convencionalismos más superficiales de la retórica romántica, cúmulo de efectismos y tópicos epatantes, aquélla, en fin, que traiciona los principios artísticos del Romanticismo.

Los parodistas teatrales, conocedores de la concepción espectacular de los dramas románticos, diseñarán unas puestas en escena de marcado carácter paródico. En ellas traducen a un nuevo código los efectismos escénicos del discurso original, elemento prioritario de las funciones románticas. Por mediación de esta traducción, los autores crean un espectáculo paródico global de las puestas en escena románticas, en perfecta lógica tanto con la naturaleza del subtexto remedado como con el público al que va dirigido, competente más en espectáculos escénicos que en textos.

Existía la sensación de que el Romanticismo era endeble, no se asentaba sobre bases sólidas, no soportaría intacto el paso del tiempo, porque los efectismos son válidos durante períodos puntuales, de fervor revolucionario ${ }^{4}$. Pero más allá, dejan traslucir su superficialidad e inconsistencia. Estos defectos potenciarán el desarrollo de una producción satírica y paródica, que los saque a la luz y exponga su ridiculez, según el siguiente testimonio de Juan Martínez Villergas:

${ }^{4}$ No lo entendamos necesariamente en clave política. Hablamos de fervor literario, cultural, social, histórico..., en suma, epocal. 
Hay apariencias que seducen: una columna de cartón llega a parecernos de piedra, merced a la verdad de la pintura, tanto más cuanto que esta columna tiene durante algún tiempo ciertas apariencias de solidez, que debe a los cuidados que la prodigan los que se hallan interesados en su conservación; pero cuando una vez la vemos abandonada a su suerte, cuando se encuentra sola y expuesta a la furia de las lluvias que le quitan el barniz, o de los huracanes a que no puede oponer sino muy débil resistencia, cae para no volver a levantarse, y lo que es más triste: cae haciendo asomar la risa en los mismos semblantes que antes afectaban la admiración (Martínez Villergas 1991, pág. 143).

\section{Los espectáculos paródicos de la retórica romántica}

Justificadas las bases que favorecen la producción paródica del Romanticismo, no nos debe extrañar la existencia de un vasto corpus de remedos escénicos, que sistematizamos con criterios temáticos: el subtexto será el elemento base de la clasificación de las parodias. Desde esta perspectiva, establecemos dos grupos principales: las parodias de los convencionalismos o de la retórica romántica y las parodias de dramas específicos. Entre las primeras, las hay más próximas al prototipo de parodia romántica y las hay más distantes, por no circunscribirse sólo a la retórica romántica. De las más próximas destacamos Muérete... iy verás! (1837). de Bretón de los Herreros, Francifredo, dux de Venecia (1867), de Mariano Pina Bohígas, y iHorror, terror y furor!! o Victimas a granel (1904), de Manuel Arboledas. De las más distantes cabe citar Bazar de novias (1867), de Mariano Pina, La abuela (1884), de Ricardo de la Vega, y La venganza de don Mendo (1918), de Pedro Muñoz Seca.

De todos estos espectáculos paródicos solamente abordaremos, según anticipamos arriba, el estudio de los signos del texto espectacular, que contribuyen a potenciar la dimensión escénica del texto y a desarrollar la parodia de las puestas en escena románticas. Será el método que nos permita aproximarnos a la línea de historia de los espectáculos paródicos que sostenemos.

El primer ejemplo más notable de puesta en escena paródica del Romanticismo es Muérete... iy verás!, de Bretón de los Herreros, estrenada el 27 de abril de 1837 en el madrileño teatro del Príncipe, de la que se realizaron 34 funciones consecutivas, cifra muy elevada en su contexto. Este dramaturgo sintetizó los tópicos recurrentes del mal Romanticismo (Llorens 1979): muertes a manos airadas, raptos, conatos de estupor, rufianismo, meretrecismo, fanatismo y furias del abismo, que definen a un Romanticismo que se excede a sí mismo. Se trata de una relación de elementos que adquieren mayor virulencia paródica expuestos directamente en el escenario. Más allá de una parodia de Los amantes de Teruel, de Hartzenbusch (Escobar 1995), cabe entenderla como parodia del Romanticismo, porque recoge tópicos y motivos románticos comunes a la 
filosofía y retórica del movimiento. Escénicamente tienen su expresión en los siguientes efectos: las interpretaciones afectadas de los actores, que han de traducir al código paródico los signos paraverbales, quinésicos y proxémicos de los espectáculos románticos, la tramoya de las apariciones espectrales entre truenos y relámpagos, y el repique de las campanas tocando a muerto, en contraste con la música de baile, remiten paródicamente a recursos escénicos usuales de las puestas en escena románticas, que son fácilmente identificables por los espectadores del remedo.

Un segundo ejemplo de parodia prototípica del Romanticismo es Francifredo, $d u x$ de Venecia (1867), en la que Mariano Pina Bohígas toma como referencia los dramas históricos románticos y los tópicos de la retórica del movimiento, apreciables en el subtítulo de la parodia: «melodrama tétrico-terrorífico». Desde el punto de vista espectacular, contribuyen al efecto paródico los decorados ${ }^{5}$, el vestuario ${ }^{6}$, los sonidos (ronquidos, bombazos, castañuelas...), la música estridente y, sobre todo, la interpretación de los actores, de la que destacamos la de los célebres Arderíus, Cubero, Orejón, Castillo y Hueto, especializados en los géneros cómico-bufos y habituales en los repartos de parodias. Estos elementos en su conjunto, aplicados a una trama acaecida en Venecia en 1571, operan reiteradas rupturas del decoro y degradaciones, y constituyen, en consecuencia, una puesta en escena distante de la solemnidad de los espectáculos históricos románticos.

De distinta naturaleza, aunque igualmente prototípica, es la parodia de Manuel Arboledas Horror, terror y furor, o víctimas a granel, estrenada en el almeriense teatro Variedades el 28 de diciembre de 1904. Fue puesta en escena por la compañía de Ramón Santoncha ${ }^{7}$, obteniendo un «éxito extraordinario», según la edición manejada ${ }^{8}$. Dada la intrascendencia del texto, sólo escénicamente podría tener algún valor. Es imprescindible tener en cuenta que la representación tuvo lugar el día de los Santos Inocentes, puesto que de otro modo difícilmente podríamos dar explicación al cúmulo de despropósitos que hacen de su puesta

${ }^{5}$ A modo de ejemplo, la acotación del primer acto describe una sala palaciega veneciana, en una de cuyas paredes penden una guitarra y una bandurria. Además del guiño localista, estos elementos tendrán función paródica en el trascurso de la trama. El segundo acto se ubica en la sala de sesiones del consejo, en la que encontramos «palangana, palanganero y toalla».

'Aparecen personajes que visten paródicamente de incógnito, así como otros que llevan adornos de pirata (vendas en los ojos).

${ }^{7}$ Esta compañía estuvo formada el día del estreno de la parodia por tres actrices (Álvarez, González y Jordán) y ocho actores (Montosa, Velasco, Banquels, Barberá, Simondini, Rodrigo, Albentosa y Sansano).

${ }^{8}$ Este dato, en realidad, responde más a un formulismo que fomente la venta del libreto que a la realidad del estreno (Beltrán 1992). 
en escena un ejemplo de broma teatral ${ }^{9}$. Todos los principales efectismos escénicos románticos tienen cabida en este «disparate cómico-bufo-espeluznante»: las diferentes formas de mortalidad escénica, sea el asesinato, sea el suicidio, sea la muerte ocasionada por un fenómeno de la naturaleza (un rayo), las interpretaciones pasionales, los espacios tópicos y la tramoya de viento, relámpagos y truenos aparecen en este espectáculo, donde los actores deben forzar la hiperactuación y explicitar la metateatralidad, que, a su vez, resulta potenciada en esta parodia por el recurso del teatro dentro del teatro. El público, en consecuencia, no ve una función teatral, sino que asiste como espectador de una ficticia representación de un drama romántico, de modo que obtiene una perspectiva aún más distanciada de los recursos convencionales de la retórica romántica, que Manuel Arboledas saca a la luz.

En segundo lugar, habíamos citado las parodias no prototípicas o más distantes de la retórica romántica. Esta circunstancia parte de que no fueron concebidas como reacción al discurso romántico, sino que éste constituye un componente esencial del espectáculo paródico, pero no el único. Estos remedos presentan varios subtextos, correspondientes a discursos originales diversos. Sus identificaciones no son tan explícitas y exigen mayor esfuerzo interpretativo por parte de los espectadores, que han de poner a prueba su competencia teatral en un complejo, aunque nunca imposible, juego literario. El primer espectáculo al que aludimos en esta categoría es la zarzuela Bazar de novias, de Mariano Pina, con música de Cristóbal Oudrid, estrenada en el teatro Variedades (Bufos) el 9 de marzo de 1867. En este remedo identificamos dos subtextos: el discurso de la alta comedia y el discurso romántico. El autor presta más atención a los signos del texto escrito, pero desde el punto de vista espectacular también es posible rastrear la parodia del Romanticismo: la burlesca necesidad romántica de perfeccionamiento a través de la amada supone interpretaciones escénicas caricaturescamente arrebatadas, de irrisoria pasión mal entendida. Éstas son llevadas a cabo por los habituales actores del repertorio de los Bufos: la consolidada pareja cómica Arderius y Orejón y las actrices Hueto y Fontfrede. Sus actuaciones marcadamente histriónicas e hiperbólicas, acompañadas de una serie de signos paródicos ${ }^{10}$, generan una escenificación que excede la retórica espectacular romántica, ceñida, en este caso, a los conflictos sentimentales.

"Así lo entendieron los actores, según deducimos de la nota que acompaña a la lista de actores aparecida en la edición consultada: «El Sr. Banquels y el Sr. Barberá desempeñaron tan insignificantes papeles por complacencia y en un rasgo de buen humon».

${ }^{10}$ Especial relevancia tiene el vestuario: las jóvenes casaderas aparecen con diversos vestidos regionales, que, además de caracterizarlas, suponen un guiño burlesco al interés romántico por lo autóctono. 
El segundo espectáculo que incluimos en este grupo es el sainete lírico $L a$ abuela, de Ricardo de la Vega, con música de Chueca y Valverde, estrenado el 21 de abril de 1884 en el madrileño teatro Variedades. El subtexto principal es la comedia de enredos, pero la retórica romántica asoma como trama secundaria, desarrollada por tres personajes: el celoso protector de su hija, don Casto, la joven dama romántica, Isabel, y el pretendiente, Diego. El desarrollo paródico de esta trama está asegurado desde el punto de vista del texto espectacular, como consecuencia de los actores encargados de los papeles de estos tres personajes, que respectivamente fueron Luis Carceller, Juana Espejo y Salvador Lastra. Éstos, curtidos en el fenómeno teatral de los Bufos, se habian afianzado en la interpretación cómica y dominaban las técnicas caricaturescas de los signos paraverbales, quinésicos y proxémicos. Son los requisitos indispensables para caracterizar afectadamente la verborrea romántica, explotar la comicidad de los gestos y de los movimientos y desarrollar con propiedad paródica los tópicos suicidios, motivados por tragicómicas anagnórisis.

El último espectáculo paródico que citamos en el grupo de las parodias no exclusivas de la retórica romántica es La venganza de don Mendo, de Pedro Muñoz Seca, estrenada el 20 de diciembre de 1918 en el teatro de la Comedia. Este astracán presenta una compleja estructura paródica, integrada por las referencias al teatro clásico, al romántico, al neorromántico y al poético. Aparte de la traducción de código de la retórica romántica que aplica a elementos del texto escrito como la expresividad, los temas, la ideología, los personajes heroicos y las situaciones concretas de diversos dramas románticos, esta parodia desarrolla el discurso espectacular a través de los siguientes elementos: los decorados, a cargo de los escenógrafos Blancas y Amorós, remedaban los decorados tópicos de los espectáculos románticos (sala de armas de un castillo, un campamento militar y una cueva-cementerio tétrica); la interpretación de Juan Bonafé, encargado del personaje de don Mendo, aportó la comicidad necesaria al antihéroe romántico; y efectismos recurrentes como las hiperbólicas emanaciones de sangre, las muertes tremebundas o los ridículos desmayos remiten de modo inequívoco a motivos escénicos de los espectáculos románticos.

\section{Espectáculos paródicos de dramas románticos}

Más numeroso es el grupo de parodias de dramas románticos específicos. La vigencia de los principales títulos románticos en escena durante la segunda mitad del siglo XIX permitió que el público mantuviese un nivel alto de competencia teatral y fuese capaz, en consecuencia, de identificar las situaciones concretas de los espectáculos remedados. Encontramos parodias de Los amantes de Teruel, de Hartzenbusch, de El trovador y de Venganza catalana, ambas de Antonio García 
Gutiérrez, de Macias, de Mariano José de Larra, de Don Álvaro o la fuerza del sino, del duque de Rivas, y de Don Juan Tenorio e Inconfeso, traidor y mártir, de José Zorrilla. Omitiremos el estudio de las parodias de Don Juan Tenorio, por las causas arriba apuntadas, así como el de Rábano el sastre o la fuerza de las tijeras, remedo del drama del duque de Rivas, y La venganza de Catana, de Juan de Alba, parodia de Venganza catalana, como consecuencia de no haber localizado las ediciones de éstas últimas, aunque sabemos de su existencia ${ }^{11}$.

Cuatro fueron las parodias que suscitó el espectáculo romántico Los amantes de Teruel, de Hartzenbusch (Peláez 2004): Los amantes de Chinchón (1848), de Juan Martínez Villergas, Miguel Agustín Príncipe, Gregorio Romero Larrañaga, Eduardo Asquerino y Gabriel Estrella, Estrupicios del amor (1849), de Mariano Pina, Los novios de Teruel (1867), de Eusebio Blasco, e Isabel y Marsilla (1887), de Ángel María Segovia. De ellas la primera no pudo ser representada en ningún teatro oficial, no tanto como consecuencia de sus escenas inmorales, que eran frecuentemente toleradas en las funciones del teatro de la Cruz, sino a causa de razones político-ideológicas: tres de sus autores, Juan Martínez Villergas, Gregorio Romero Larrañaga y Miguel Agustín Príncipe, tenían abiertos expedientes de censura y, además, habían sido vetados por una de las revistas de más peso institucional, La Censura. No obstante su ausencia escénica, no podemos negarle la función paródica de su discurso espectacular, remedo de la función romántica en los siguientes términos: a pesar de que no podamos hablar de actores concretos, es posible indicar los rasgos paródicos que caracterizan a los actores, como la caricatura de los signos paraverbales del tono, timbre y ritmo (cómica frialdad de Ruperta al anunciar su propia muerte, por ejemplo), la radicalización de los signos quinésicos (gestos ridículamente trágicos de Diego), el desarrollo grotesco de los signos proxémicos (escena final de sucesión de muertes) y el voluntario descuido de los signos de vestuario, maquillaje y peinado (antihéroes sucios y desarreglados); en segundo lugar, el decorado vulgar, representativo de una tienda de fósforos y, posteriormente, una cuadra, no es el marco adecuado para desarrollar una acción romántica y carece de la propiedad del espacio escénico del subtexto remedado; un tercer elemento paródico del discurso espectacular son los efectismos tales como la resucitación de cadáveres, recurso recurrente en parodias románticas, y la iluminación tenue, que, en vez de aportar misterio, provoca una ruptura del decoro al focalizarse el punto de luz sobre las figuras de los antihéroes.

"Ana María Freire López (1995) recoge la información sobre Rábano el sastre o la fuerza de las tijeras, anunciada por La Época en 1850, y Salvador Crespo Matellán (1979) constata la existencia de La venganza de Catana. 
Mariano Pina sí consiguió estrenar su parodia Estrupicios del amor en 1849 , en el madrileño teatro Español, a pesar de no ser tampoco ejemplar moralmente. Tomó como subtexto la adaptación del drama romántico que realizó el propio Hartzenbusch en 1849, de la que suprimió algunos pasajes. Este remedo apenas fue relevante para la historia de los espectáculos paródicos, porque ni el autor prestó excesiva atención a los signos del texto espectacular, ni la compañía dramática que lo representó tenía experiencia en el género paródico ${ }^{12}$, como sí la tenían la de Vicente Caltañazor y Josefa Noriega en esos mismos años y, más tarde, durante las décadas de 1860 y 1870 , la de Arderíus y Orejón. Mariano Pina descuidó la puesta en escena, como apreciamos en las escasas acotaciones al respecto de signos como decorado, iluminación o elementos escénicos, y sólo atribuyó función paródica a la interpretación de los personajes antiheroicos, cuya caracterización semiótica omitimos al coincidir con la de Los amantes de Chinchón.

Más relevante es el «drama lírico-burlesco» Los novios de Teruel, de Eusebio Blasco, con música de Arrieta, estrenado el 24 de diciembre de 1867, en el madrileño teatro de los Bufos ${ }^{13}$. Desde el punto de vista de historia de los espectáculos que preside este estudio, esta parodia resulta interesante porque su puesta en escena se incardinó en el fenómeno teatral de los Bufos, auspiciado por el polifacético Arderíus, y fue representada por una compañía cómica especializada en dichas interpretaciones, de la que destacamos a las actrices Álvarez y Fontfrede y a los actores Orejón, Fuentes, Castilla y Arderíus ${ }^{14}$. Éstos mostraron las cualidades óptimas para representar parodias, en las que conocer el subtexto es imprescindible para interpretar adecuadamente personajes paródicos, y supieron granjearse la atención de los espectadores, que respondieron a las expectativas generadas (Íñiguez 1999). La mera presencia de la pareja Arderíus y Orejón era aval suficiente para garantizar una puesta en escena hilarante, de naturaleza en este caso paródica. Desarrollaron las habilidades de la interpretación caricaturesca, hiperbólica, bufa, que exigen más preparación de la que a simple vista pueda parecer: la desmesurada exageración puede comportar el rechazo del público si los actores no saben adecuarse a la situación paródica que preside el acto de comunicación dramática.

12 Dicha compañía estuvo integrada por María Valentín, María Muñoz, Joaquina Barroso, Pelegrín Ros, Saturnino Blen, Francisco Balestroni y Francisco Argüelles.

${ }^{13}$ La obra fue censurada por Narciso Serra, aunque, tras aceptar Eusebio Blasco las supresiones que aquél indicó, pudo representarse sin inconvenientes.

${ }_{14}$ A varios de ellos (Arderíus, Orejón y Fontfrede) los vimos ya en el reparto de Bazar de novias. pero, como es lógico, no se restringieron a la parodia romántica, sino que aparecieron en espectáculos paródicos varios, desde el punto de vista del subtexto remedado, de acento marcadamente cómico. 
No sólo las interpretaciones histriónicas, afectadas, ridículas y, en general, voluntariamente artificiales cumplen la función paródica del discurso espectacular de Los novios de Teruel. Es, en efecto, el recurso principal, pero no podemos olvidar una serie de elementos que contribuyen a la parodicidad de la puesta en escena: el decorado nos remite a uno de los tópicos románticos por excelencia, el del jardín de los enamorados, en el que, en esta ocasión, el ambiente desprende el olor del «cardo y la patata» y el espacio arbolado propicia juegos de escondite, que generan evidentes rupturas del decoro respecto del tópico romántico; también los números musicales pueden disponer de función paródica, como el pasaje en que los actores aparecerán, al cantar, «temblando cómicamente y como si tuvieran ataque de nervios) (C I, E XII).

Un último ejemplo de posicionamiento paródico ante el drama de Hartzenbusch lo constituye El amor de un boticario (1872), de Ángel María Segovia, que, tras su éxito inicial ${ }^{15}$, fue refundida como zarzuela, con música de Rafael Taboada, en 1887, con el nombre de Isabel y Marsilla, y representada en el teatro Eslava el 9 de diciembre de ese año. De los cuatro remedos, éste es el más distanciado del drama romántico, aunque presenta los elementos imprescindibles para integrarlo en la saga paródica de Los amantes de Teruel. Desde el prisma espectacular, la caricaturización escénica de las interpretaciones románticas de los personajes del drama de Hartzenbusch resultó efectiva gracias a la actuación de una de las compañías cómicas de más prestigio en su marco. Participaron en esta representación actores de la talla de Emilio Carreras, que llevaba realizando el papel protagonista desde 1874, previamente a su refundición en zarzuela, y Olona, especializado en interpretaciones de graciosos al modo del teatro clásico. A éstos acompañaron actores de reconocidas habilidades cómicas como Julián Ruiz y Mariano Larra, frecuentes en los repartos de parodias. A ellos van dirigidas las acotaciones de dicción (pronunciaciones con infantil coquetería o con ridícula majestad, que remedan el discurso romántico), de gestos (reacciones de sorpresa cómica, de preocupación risible, lloriqueos...), de distancias y movimientos (interposiciones del padre entre los amantes, cortesías ridículas, huidas despavoridas...) y de caracterizaciones de vestuario (Fernando, el paródico héroe romántico, aparece ridículamente vestido de levitín y sombrero de paja, adornado con cintas de colores), que, junto con los apartes, el decorado escénico (nuevamente aparece el jardín tópico romántico aplicado a la situación paródica) y la música (sus cinco números posibilitan pasajes caricaturescos de eficacia escénica), construyen una puesta en escena paródica y distante de la espectacularidad romántica.

15 El autor afirma en nota inicial de la edición manejada que esta parodia se representó en diversos teatros de Madrid más de quinientas veces. 
Dos fueron los dramas remedados de Antonio García Gutiérrez: El trovador y Venganza catalana. Del.primero hubo tres parodias y del segundo dos, aunque ya indicamos que de Venganza catalana sólo hemos localizado una. Llama la atención que la primera parodia de su drama más célebre fuera escrita por el propio Antonio García Gutiérrez. Se tituló Los hijos del tío Tronera y fue representada en el teatro de la Comedia en 1849. Este remedo no trascendió los objetivos lúdicos del género, concretados en el juego literario de identificaciones del subtexto. Como espectáculo, sólo podía ejercer de reclamo la autoría, porque ni la compañía cómica ni la parodicidad escénica aportan valor a la puesta en escena. De la compañía sólo merecen ser citados Joaquín Ruiz y Antonia Suárez, que participaron en espectáculos paródicos varios durante la segunda mitad del siglo XIX. Por otro lado, el autor no prestó excesiva atención al texto espectacular y desarrolló más la función paródica de los signos del texto dramático escrito. No obstante, podemos identificar algunos elementos que confirman la faceta paródica del nivel escénico: la dicción andaluza vulgar como signo paraverbal que representa la ruptura del discurso romántico; los apartes escénicos de contenido cómico, como convención teatral; los gestos ridículamente trágicos motivados por una circunstancia inesperada para los personajes, pero previsible para los espectadores, gracias a su competencia teatral; los desmayos improcedentes y las muertes histriónicas, como signos proxémicos recurrentes en las parodias románticas; y los equívocos cómicos provocados por la aparición escénica de embozados.

El 10 de agosto de 1889 se estrenaba en el madrileño teatro de la Infantil la zarzuela paródica El esquilaor, de Federico Montañés, con música de Alejandro Manzano. Aprovechó tanto la fama del drama romántico como de la ópera de Verdi, que fue la tercera más representada en el teatro Real durante el período 1854-1825, después de Aida y Rigoletto (Ruiz 1985). No fue representada por una compañía de prestigio, y solamente merecen citarse los actores Viñas e Hidalgo y la actriz Sanz, que dominaban la técnica de la improvisación y el histrionismo de interpretaciones grotescas ${ }^{16}$. A ellos confía el autor el desarrollo de la función paródica del texto espectacular, puesto que apenas incorpora acotaciones que especifiquen la caracterización burlesca. Únicamente al final del remedo, con el objetivo de detallar el desenlace y obtener un buen efecto de cara al público, añade extensas acotaciones en las que incluye referencias a los signos del actor (dicción, gestos, movimientos, vestuario), del espacio escénico, de los objetos y de la luminosidad. Esas indicaciones se erigen en recetarios de cómo parodiar una

"A ellos se debe la incorporación al espectáculo de una serie de recursos escénicos de eficacia cómica, fruto de su improvisación. Estos añadidos los recoge el autor en acotaciones, indicando qué actores los han ideado. 
puesta en escena romántica, ya que no queda ningún tópico del espectáculo de Antonio García Gutiérrez sin contrapartida paródica.

No nos detendremos en La noche de El trovador, de Tomás Luceño, porque no remeda el espectáculo romántico, sino que, tomando como punto de ubicación una representación del drama de Antonio García Gutiérrez, da paso a una acción dramática escasamente ligada a la romántica, sin que haya un juego literario paródico con los signos del texto espectacular. Se incardina en la línea de espectáculos como La cómico-mania, de Eduardo de Lustonó y Eduardo Saco, y La noche del Tenorio, de Felipe Pérez Capo, cuyos objetivos, más allá del juego teatral, apuntan al marco sociocultural.

El otro espectáculo de Antonio García Gutiérrez remedado fue su tardío drama histórico Venganza catalana (1864). Francisco de Paula Sinquemani compuso La venganza de un gitano, en cuyo manuscrito no aparecen los datos de fecha, lugar de representación y compañia dramática ${ }^{17}$. El parodista propone un remedo íntegro del espectáculo romántico. En primer lugar, en contraste con los espacios solemnes del drama histórico, el escenario representa durante las seis primeras escenas una posada $y$, en las restantes, el patio de un corral, donde una multitud de majos y majas jalean con palmas y guitarras la fiesta de celebración de matrimonio que acarreará el sangriento desenlace. En estos espacios arrománticos, observamos un trasiego escénico de actores embozados, otros que se esconden debajo del escaso mobiliario, fallidos intentos de escapada a toda prisa, apartes escénicos, declamaciones paródicamente trágicas, muertes atroces por su ridiculez y bofetadas risibles, entre otros elementos, que confirman a La venganza de un gitano como parodia de Venganza catalana y, en general, de la retórica espectacular del Romanticismo.

Mariano José de Larra también fue víctima de los parodistas. Su Macias posibilitó la creación del remedo Matias o el jarambel de Lucena, de Ramón Franquelo. Apareció en 1850 en un volumen de composiciones literarias de carácter misceláneo titulado Risa y llanto, y desconocemos si subió a escena. Su texto espectacular es sencillo y responde a las intenciones lúdicas del género. Los actores deben desarrollar una doble función: por un lado, evidenciar al público que se halla en una función teatral, gracias a los comentarios metateatrales, que provocan la ruptura de la cuarta pared y, en consecuencia, de la ilusión dramática; por otro lado, caracterizar paródicamente a los personajes, a través del remedo del estilo interpretativo romántico, basado en la caricatura paraverbal, quinésica y proxémica y en los recursos cómicos del vestuario. Al igual que vimos para

${ }^{17}$ No hemos localizado ninguna edición de imprenta del texto. Quizá haya que pensar que no fue llevada a escena, aunque ello no es óbice para indicar en qué sentido esta obra se erige en parodia del espectáculo de Antonio García Gutiérrez. 
El esquilaor, las dos últimas escenas aumentan la parodicidad escénica, a fin de obtener un desenlace que, tras la acumulación de efectismos, impresione al público. El decorado, por otro lado, también incide en la parodia de la solemnidad de la puesta en escena del drama de Larra. El espacio romántico deviene en una "sala pobre, sin mueble alguno», carente de dependencias nobles o edificaciones lujosas, en lógica coherencia con el posicionamiento paródico que preside el acto comunicativo.

Finalizamos este grupo de remedos de dramas románticos específicos con Traidor, inconfeso y bufo, «profecía cómico-lírica en un acto escrita por varios abonados al teatro de la Zarzuela», con música de Reparaz, estrenada en el madrileño teatro de Paul-Bufos el 23 de octubre de 1872. La explicitud del título nos remite a Traidor, inconfeso y mártir, de José Zorrilla. No obstante, de este drama no queda más que una serie de correspondencias metafóricas desde el punto de vista del argumento y de los motivos temáticos: la historia del sacrificio del rey don Sebastián y motivos como la fidelidad a un juramento y la abnegación se sustituyen por la historia del pretendido sacrificio del alegórico personaje del género bufo, que, en este caso, como contrapunto paródico, carece de la firmeza necesaria y no cumple su juramento de disolución del género. La comicidad que caracteriza el texto se halla presente igualmente a nivel escénico, potenciada por la interpretación de Ramón Rosell, que hizo de género bufo. Sus habilidades histriónicas, su capacidad de improvisación y sus innatas dotes cómicas hicieron de él uno de los actores predilectos de los parodistas, a pesar de carecer de formación dramática. El personaje principal del género bufo permitió su lucimiento paródico, al que coadyuvó un caricaturesco vestuario ${ }^{18}$. A ello hay que sumar efectos escénicos como el «poético y risueño» decorado, la música, que recuerda pasajes de espectáculos bufos como el Robinson y de óperas como Rigoletto, los sonidos estrepitosos en contraste con acordes solemnes, los bailes grotescos de seguidillas y zapateados, y la hoguera que alimentan en la escena con los libretos de obras bufas. Estos recursos hacen de Traidor, inconfeso y bufo un espectáculo caricaturesco, opuesto a la magnificencia de las puestas en escena románticas de drama histórico' ${ }^{19}$.

${ }^{18}$ En acotación se nos indica que el género bufo aparece «vestido de alta etiqueta: frac negro y corbata blanca, la peluca rubia y una corona de laurel. Corona y palma en caricatura. Sale majestuosamente y saluda con respeto» (E I).

${ }^{19}$ El interés de esta pieza radica, no en la parodia del subtexto romántico, sino en el testimonio escénico que supone de la polémica teatral que la empresa de los Bufos madrileños de Arderíus suscitó en su contexto. Se erige en satírica reacción de las críticas que tachaban al género bufo de enemigo del arte y generador de la degradación del público. No desarrollamos esta problemática porque queda fuera del ámbito de estudio de este trabajo, centrado en la parodia romántica, pero dejamos constancia de su relevancia para una futura historia de los espectáculos teatrales del siglo XIX. 
Hemos presentado, en conclusión, desde un punto de vista sistemático, y necesariamente esquemático, nuestra propuesta de historia de los espectáculos teatrales paródicos del Romanticismo. En ella, por un lado, los subtextos son remedados como espectáculos que son, y no sólo textos ${ }^{20}$, y, por otro, los signos del nivel espectacular poseen una fuerza paródica igual, e incluso superior, a los del nivel textual. La relevancia teatral del movimiento romántico favoreció la proliferación de remedos escénicos a través de un dilatado período que, significativamente, coincide con los límites de la época dorada del género paródico. Éstos vienen marcados, en su inicio, por el estreno de Muérete... iy verás! en $1837 \mathrm{y}$, en su fin, por el de La venganza de don Mendo en 1918. Una historia de los espectáculos paródicos posibilitará una aproximación más realista a la realidad teatral de la segunda mitad del siglo XIX y principios del XX, no sólo porque se enfoque el género dramático desde la obligada concepción espectacular, sino porque, dada la naturaleza metateatral de la parodia, obtendremos datos complementarios que justifiquen qué espectáculos teatrales gozaron de mayor difusión o prestigio escénicos y formaron parte esencial de la competencia dramática del público.

${ }^{20}$ De este modo los parodistas no traicionan la filosofía romántica de la concepción escénica, que primaba la espectacularidad (Caldera 1999). Si el romanticismo primaba la idea de teatro como espectáculo, los parodistas, en consonancia, debían remedar no un texto, sino un espectáculo, creando, a su vez, una puesta en escena metateatral. Se obtienen así efectos más directos sobre el público, enfocados no tanto a la razón como a las sensaciones. 


\section{BIBLIOGRAFÍA}

Álvarez BARRIENTOS, Joaquín, 1995. «Las ideas de Martínez Villergas sobre la risa en La risa, enciclopedia de extravagancias», en AAVV., Romanticismo 5 (La sonrisa romántica), Roma, Bulzoni, págs. 9-15.

Beltrán, Pablo, 1992. Salvador María Granés, autor del género chico y periodista satírico, Madrid, Universidad Complutense.

Bobes Naves, María del Carmen, 1997. Semiología de la obra dramática, Madrid, Arco/Libros.

CALDERA, Ermanno, 1995. «La sonrisa romántica», en AAVV., Romanticismo 5 (La sonrisa romántica), Roma, Bulzoni, págs. 43-49.

- 1999. «Siglo XIX», en Andrés Amorós y José María DíEz Borque (coord.), Historia de los espectáculos en España, Madrid, Castalia, págs. 87-104.

CRESPO MATELLÁN, Salvador, 1979. La parodia dramática en la literatura española, Salamanca, Universidad de Salamanca.

ESCOBAR, José, 1995. «¿Es que hay una sonrisa romántica? Sobre el Romanticismo en Muérete... jy verás! de Bretón de los Herreros», en AAVV., Romanticismo 5 (La sonrisa romántica), Roma, Bulzoni, págs. 85-96.

Freire López, Ana María, 1995. «El teatro se ríe de sí mismo: las parodias de los dramas románticos», en AAVV., Romanticismo 5 (La sonrisa romántica), Roma, Bulzoni, págs. 113-115.

ÍNıGUEZ BARRENA, Francisca, 1999. La parodia teatral en España (1868-1914),

Sevilla, Universidad de Sevilla.

LLORENS, Vicente, 1979. El romanticismo español, Madrid, Castalia.

Martinez Villergas, Juan, 1991. Textos picantes y amenos, Arturo Martín VEGA (ed.), Salamanca, Junta de Castilla y León.

PelÁEz PÉREZ, Víctor Manuel, 2004. «Los amantes de Teruel de Hartzenbusch en solfa»)», Stichomythia, 2.

Ruiz Silva, Carlos, 1985. «Introducción», en Antonio García Gutiérrez, El trovador, Madrid, Cátedra.

SÁNCHEZ SALAS, Bernardo, 1998. «Representando a Bretón», en Miguel Ángel Muro (coord.), Actas del Congreso Internacional Bretón de los Herreros: 200 años de escenarios, Logroño, Instituto de Estudios Riojanos, págs. 145161.

Serrano, Carlos, 1996. Carnaval en noviembre, Alicante, Instituto Juan GilAlbert. 